\title{
Calculating Employee Compensation Using An Economic Principle
}

Puneet Jaiprakash, Ph.D., Minnesota State University at Mankato, USA

\begin{abstract}
Although methods for determining the compensation of a new employee are standardized, those for adjusting an employee's compensation over a period of time are not well established. This paper develops an intuitive method for calculating the minimum amount by which an employee's compensation must be adjusted taking into account changes in economic conditions since the start of employment. It then translates this result into a worksheet that computes compensation using employee specific information-starting salary, length of employment, and frequency of compensation adjustments.
\end{abstract}

Keywords: Salary; Compensation; Inflation; Purchasing Power; Financial Crisis

\section{INTRODUCTION}

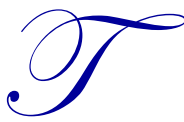

he compensation package provided by an employer plays a critical role in hiring and retaining employees. Low compensation results in unwanted employee turnover and high compensation results in wasted financial resources; determining the correct amount is therefore important. For new employees, the cash compensation is determined by adjusting industry-level survey data for various factors such as the firm's size, geographic location, and employee's education and certification (AFP Compensation Report (2013), Murphy (1999), Newton (2002), Pomering and Lyon (2000)). To remain competitive, compensation packages are revised after a few years (once every year, or once every two years, etc.) using the maturity curve method. This method first uses survey data to estimate the relationship between compensation and number of years since BS degree. It then computes an adjustment based on the (i) difference between the employee's current compensation and that obtained from the estimated model, and (ii) company's philosophy on compensation. This process is repeated for each job title in the company. Unfortunately, this method has several drawbacks. First, it relies on survey data which might suffer from several problems. For example, the sample size might not be large enough to represent the job title being evaluated, the sample might be composed of companies that are not considered labor market peers, or the data might not be current and thus not reflect current labor market trends (Ch. 9 in Berger and Berger (2008)). Second, it is appropriate for only employees that have spent a few years in a job title but not for those that have spent many years in that title (e.g. an employee who has been a Junior Financial Analyst for the past 15 years). The reason is that after a few years the good performing employees will have been promoted to management positions. The survey sample will therefore consist of only lower-performing and lower-paid employees. Using the curve for such employees will therefore lead to low compensation for them.

This paper develops an intuitive method to calculate an employee's compensation thereby avoiding drawbacks of the maturity curve method-use of survey data and applicable to only a subset of employees. The cash compensation in any year consists of not only the starting salary but also merit and incentive payments, and an adjustment for a change in the cost-of-living. Since performance evaluation procedures used for determining merit and incentive payments vary significantly across firms (Ch. 8 in Berger and Berger (2008)), it is difficult to find a representative method; hence, the paper focuses on the cost-of-living adjustment. The basic idea is to adjust an employee's compensation so that his/her purchasing power-a measure of what one can purchase with a given amount of money at a particular price level-remains constant over time. In particular, the starting salary allows an employee to purchase a particular quantity of goods and services based on the time-of-hire price level. Going forward, as prices change in response to economic conditions, the employee's purchasing power will also change. Therefore, a reasonable method would be to adjust his/her salary so that the purchasing power remains identical to 
that at time-of-hire. In other words, the compensation is adjusted such that the employee is able to buy the same quantity of goods and services at current prices as at the start of employment. The assumption of maintaining a constant purchasing power is only made for ease of exposition; the framework developed herein can be easily modified to incorporate changes - increases or decreases - in purchasing power over time.

Next, the paper uses this result to develop a worksheet that can be used by employers to compute the cash compensation for their employees or by employees to gauge the appropriateness of their current compensation. The recent financial crisis demonstrated the drawbacks of current compensation models and has drawn the attention of regulators and policymakers towards reforming compensation. For example, a recent report (Institute of International Finance (2009)) recommended transparent compensation structures to shape employee behavior. The methodology developed in this paper is simple, can be easily explained to employees, and facilitates a clear delineation between the quantitative and discretionary aspects of compensation. A better understanding of their compensation will positively influence employee behavior and result in a better alignment of interests between shareholders and managers. This in turn will help maximize firm value and prevent future financial crises.

The remainder of the paper is organized as follows. Section II discusses and distinguishes among the various components of cash compensation. Section III uses a numerical example to explain the intuition underlying the methodology for computing the normative cash compensation. Section IV translates this intuition into a worksheet that computes compensation using employee specific information-starting salary, length of employment, and frequency of compensation adjustments. Section VI concludes.

\section{COMPONENTS OF CASH COMPENSATION}

Total compensation for new employees consists of cash compensation and a benefits package that includes health and life insurance, paid vacation time, and a retirement plan. Cash compensation in turn comprises of two components - starting salary (salary hereafter) and incentive payment - the proportion of which varies based on job title $^{1}$. The salary is a guaranteed payment received each year for services performed; incentive payment, on the other hand, may or may not be received each year. For example, the firm's performance - as measured by financial metrics such as Operating Income, EBITDA, Revenues, and Profits or soft measures such as project completion and customer satisfaction - might be better in some years than in others. Incentive pay is designed to reward such superior performance by making a one-time payment to an employee, a team, a business unit, or a division. Although an employee does not know whether he/she will receive an incentive payment, the dollar amount can be calculated ex-ante since it is based on a pre-specified formula (e.g. a said fraction of Revenues in excess of a threshold). Thus, this component is designed to positively influence an employee's behavior on the job by providing a monetary upside. reasons:

Employers typically adjust the cash component of total compensation every few years for the following

Changes in Cost Of Living: Over time, prices in the economy change due to which employees are able to buy fewer or more goods and services with a given amount of dollars. The cost of living adjustment (COLA) accounts for this phenomenon and it results in a permanent change (typically an increase) in the employee's salary. In addition, it is the same for all employees regardless of their job title.

(ii) Employee's Achievements or change in his/her skillset: Over time, an employee might obtain an advanced degree (e.g. MBA), obtain a professional certification (e.g. CFA), and/or make significant contributions to the firm's profitability. A merit payment rewards such achievements. Each employee may or may not receive a merit payment, but if he/she does it always results in a permanent increase in the salary; the amount, however, is not the same for all employees. In other words, a merit payment is a permanent increase in the salary that is specific to an employee and is based on his/her past behavior. Table 1 below summarizes this discussion of the components of cash compensation.

\footnotetext{
${ }^{1}$ The AFP Compensation Report (2013) indicates that salary comprised 73-86\% of total compensation at the Executive level, $80-92 \%$ at the Management level, and 93-98\% at the Staff level.
}

Copyright by author(s); CC-BY 
Table 1: Components of Cash Compensation

\begin{tabular}{|c|c|c|c|}
\hline COMPONENT & DESCRIPTION & $\begin{array}{l}\text { EFFECT ON CASH } \\
\text { COMPENSATION }\end{array}$ & SCOPE \\
\hline Starting Salary & $\begin{array}{l}\text { Annual guaranteed payment made to an employee as } \\
\text { compensation for work done for employer. }\end{array}$ & N/A & Job-specific \\
\hline $\begin{array}{l}\text { Cost of Living } \\
\text { Adjustment }\end{array}$ & $\begin{array}{l}\text { Payment to employees that accounts for the fact that } \\
\text { price changes in an economy result in employees being } \\
\text { able to buy fewer or more goods and services with a } \\
\text { given amount of dollars. }\end{array}$ & $\begin{array}{c}\text { Permanent } \\
\text { increase/decrease }\end{array}$ & Firm-wide \\
\hline Merit Payment & $\begin{array}{l}\text { Payment to an employee that rewards past } \\
\text { accomplishments such as obtaining advanced degree } \\
\text { (e.g. MBA), getting a professional certification (e.g. } \\
\text { CFA, CPA, etc.), or making significant contributions to } \\
\text { the firm's profitability. }\end{array}$ & Permanent increase & Individual \\
\hline Incentive Payment & $\begin{array}{l}\text { Payment made to an individual, a team, a business unit } \\
\text { or a division in lieu of good performance. Differs from } \\
\text { a Merit Payment in that it is (i) designed to influence } \\
\text { employee behavior by providing a monetary upside i.e. } \\
\text { employee doesn't know whether he/she will receive the } \\
\text { payment, but knows the dollar amount ex-ante since it } \\
\text { is based on a pre-specified formula, and (ii) typically } \\
\text { paid as a one-time lump sum payment }\end{array}$ & Temporary increase & Individual/Group \\
\hline
\end{tabular}

The above discussion suggests that an employee's cash compensation in any year will consist of not only the salary and incentive payment but also a cost-of-living adjustment and all of the merit payments received:

$$
\text { Cash Compensation }=\text { Starting Salary }+ \text { IncentivePayment }+ \text { COLA }+ \text { AllMeritPayments }
$$

Of the four terms on the right hand side, the incentive component is the only one that may or may not be received each year; thus the guaranteed payment received by an employee in any year consists of the starting salary, a COLA, and all merit payments:

$$
\text { Annual Salary }=\text { Starting Salary }+ \text { COLA + AllMeritPayments }
$$

Put differently, the annual salary is the guaranteed portion of an employee's cash compensation in any year since the start of employment. The normative annual salary (normative salary hereafter) refers to the annual salary an employee should receive; the actual amount paid by an employer need not necessarily equal the normative salary - it could be higher or lower.

\section{COMPUTING THE NORMATIVE SALARY: A NUMERICAL EXAMPLE}

The purpose of this section is to develop the intuition for calculating the normative salary via a numerical example. To this end, two simplifications are made. First, the example assumes no merit payments and focuses on developing a framework that accounts for changes in economic conditions, i.e. the COLA in Equation (2). This is motivated by the fact that methods for evaluating employee performance and determining merit payments vary across firms; therefore, it is difficult to find a representative method ${ }^{2}$. Second, the example assumes compensation is adjusted once every three years (triennial); this is the smallest interval that allows the intuition to be easily explained.

Consider an employee, say Jane, who was hired at an annual salary of $\$ 60,000$ three years ago when the price level was $120^{3}$. Her employer adjusts salaries once every three years and is currently trying to determine the annual salary for the next three years. The price level is currently at 128 and is indicated by the point labeled $t=0$ in

\footnotetext{
${ }^{2}$ See Chapter 8 in Berger and Berger (2008) for a comprehensive discussion of methods used to evaluate employee performance.

${ }^{3}$ The price level refers to the average price of goods and services consumed by a typical household; it is measured by indices such as the Consumer Price Index (CPI) or Personal Consumption Expenditures Index (PCE).
} 
Figure 1 below. The figure shows the path of a Price Index (top) and a timeline (bottom) when the employer adjusts compensation once every three years. $\mathrm{P}\left(\mathrm{P}^{\mathrm{e}}\right)$ denotes the realized (expected) value of the Index, and HCOL (ECOL) denotes the adjustment for the change in historical (expected) cost of living. $S_{i, j}^{n}$ denotes the normative salary to be paid in year $i+1$ through $j$ and is the sum of the starting salary $(\$ 60,000)$, HCOL and ECOL.

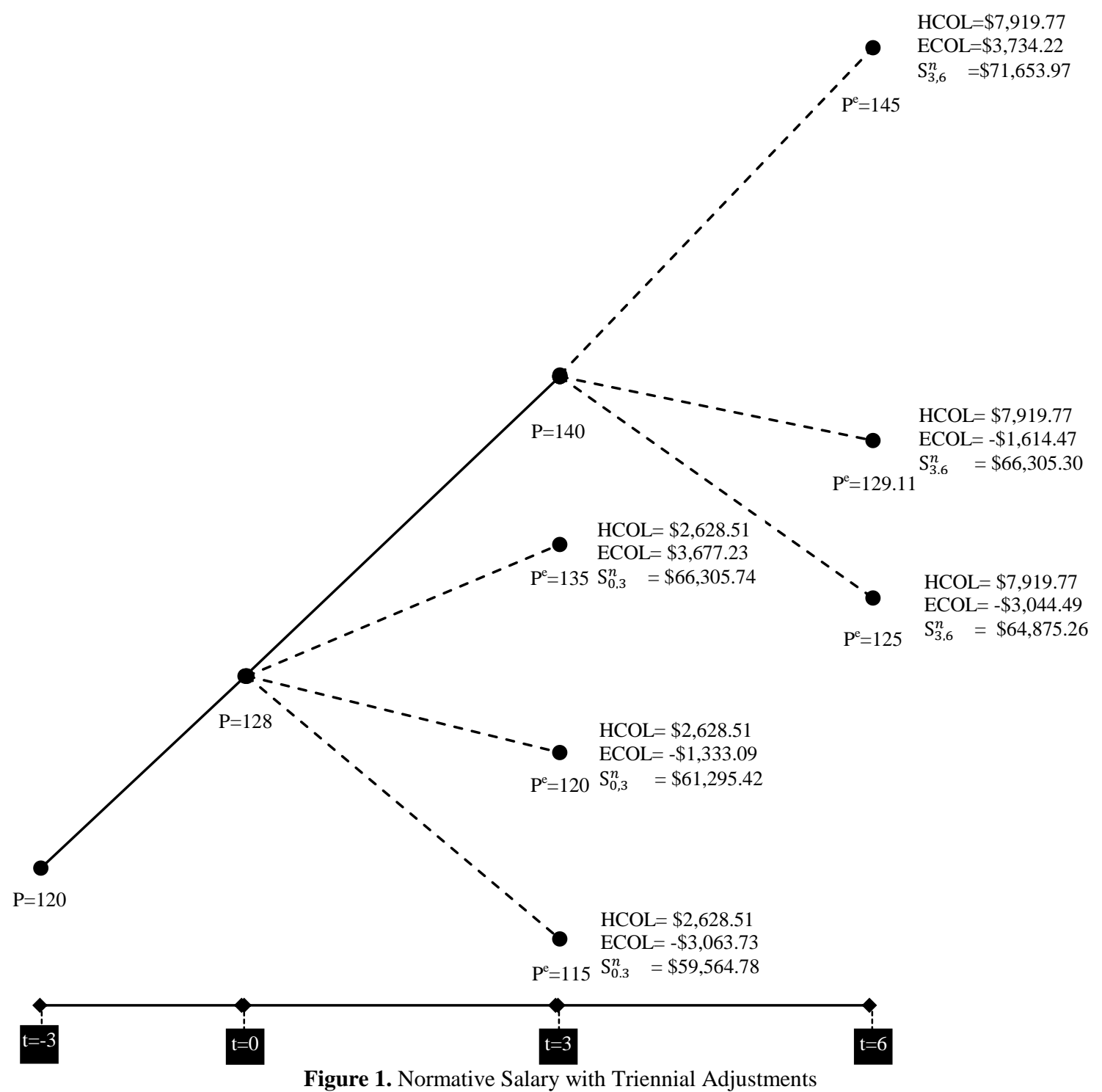

Over the last three years, prices have increased by $6.67 \%\left(=\frac{128-120}{120}\right)$ or by $2.175 \%\left(=\left(\frac{128}{120}\right)^{\frac{1}{3}}-1\right)$ each year due to which Jane's purchasing power has changed. Specifically, she could purchase $500\left(=\frac{\$ 60,000}{120}\right)$ baskets of goods at the time of hire, but a lower number in subsequent years: $489.36\left(=\frac{\$ 60,000}{120 * 1.02175}\right)$ baskets of goods two years back, $478.94\left(=\frac{\$ 60,000}{120 *(1.02175)^{2}}\right)$ baskets of goods one year back, and $468.75\left(=\frac{\$ 60,000}{128}\right)$ baskets of goods today ${ }^{4}$. To account for this, the employer needs to adjust the salary such that on average she would have been able to buy 500

${ }^{4} \mathrm{~A}$ basket refers to the goods and services consumed by a typical household. 
baskets of goods during the past three years i.e., $\frac{\frac{60,000+x}{P_{-2}}+\frac{60,000+x}{P_{-1}}+\frac{60,000+x}{P_{0}}}{3}=500$, where $x$ denotes the adjustment that accounts for the historical change in purchasing power ${ }^{5}$. Since the price level increased by $2.175 \%$ each year, it was $122.61(=120 \times 1.02175)$ two years back, and $132.63\left(=120 \times 1.02175^{2}\right)$ one year back. Substituting these values into the above equation and solving for $x$ yields a value of $\$ 2,628.51$. Notice that the employer cannot maintain the purchasing power at 500 in each year. The purchasing power is defined as the ratio of annual salary and price level, i.e. the number of baskets that can be bought with a given salary at a specific price level. Since the employer pays the same dollar amount in each year, the numerator remains constant; the denominator, however, changes since the price level changed over the last three years.

This increase of $\$ 2,628.51$ compensates Jane for the purchasing power lost over the previous three years; it does not account for the change purchasing power over the next three years. To account for this effect, the employer needs to adjust her post historical adjustment salary, such that the average purchasing power during years one, two, and three will be 500. In other words, on average, Jane must be able to buy 500 baskets during these years $62628.51+y+62628.51+y \quad 62628.51+y$

i.e., $\frac{\frac{6262}{P_{1}}+\frac{P_{2}}{3}+\frac{P_{3}}{P_{3}}}{3}=500$, where $y$ denotes the adjustment that accounts for the expected change in purchasing power.

First consider a scenario where prices are expected to increase to 135 over the next three years. Since the price level is expected to increase by $1.791 \%$ each year, it will be 130.292 in year one, 132.626 in year two, and 135 in year three. Substituting these values into the above equation and solving for $y$ yields a value of $\$ 3,677.23$. Combining both effects implies an increase of $\$ 6,305.74$; thus, the new salary is $\$ 66,305.74$. Notice that with this amount she can buy $508.901\left(=\frac{\$ 66,305.74}{130.29}\right)$ baskets in year four, $499.945\left(=\frac{\$ 66,305.74}{132.63}\right)$ baskets in year five, and $491.154\left(=\frac{\$ 66,305.74}{135}\right)$ baskets in year six. Thus, Jane's purchasing power varies in each of the next three years-high in the early years and low in the later years-but on average it equals her time-of-hire purchasing power of 500 baskets.

Now consider a situation where prices are expected to fall to 120 -the price level three years back. The historical adjustment remains the same at \$2,628.51. During the next three years Jane's purchasing power will increase since prices are expected to decrease by $2.13 \%\left(=\left(\frac{120}{128}\right)^{\frac{1}{3}}-1\right)$ each year. Using the same reasoning as above, we can see that a decrease of $\$ 1,333.09\left(=\frac{500 \times 3}{\frac{1}{125.276}+\frac{1}{122.610}+\frac{1}{120}}-\$ 62,628.51\right)$ will maintain her average purchasing power at 500. Combining this with the historical adjustment of $\$ 2,628.51$ gives us a net increase of $\$ 1,295.42(=\$ 2,628.51+[-\$ 1,333.09])$, resulting in a normative salary of $\$ 61,295.42$. Finally, consider a scenario when prices are expected to fall to 115 (i.e., below the price level three years back). In this case, the increase in salary due to loss in historical purchasing power is more than offset by the decrease in salary due to the expected gain in purchasing power. The net effect is a decrease of $\$ 435.22(=\$ 2,628.51+[-\$ 3,063.73])$, resulting in a normative salary of $\$ 59,564.78$.

In sum, the normative salary for years one through three is the starting salary augmented by a historical cost-of-living adjustment (HCOLA) for the past three years and an expected cost-of-living adjustment (ECOLA) for years one through three:

$$
\mathrm{S}_{0,3}^{\mathrm{n}}=\mathrm{S}_{\mathrm{B}}+\mathrm{HCOLA}_{-3,0}+\mathrm{ECOLA}_{0,3}
$$

Depending on the magnitude and sign of these adjustments, the normative salary can be higher than, equal to, or lower than the base salary.

\footnotetext{
${ }^{5}$ To allow for a change in the employee's purchasing power, say an increase of $1 \%$, we would equate the average purchasing power over the past three years to $505(=500 * 1.01)$ instead of 500 .
} 
Let us assume that the employer expects the price level to be 135 at the end of year three and pays Jane $\$ 66,305.74$ for years one through three. How would the employer determine the salary (at the end of year three) for years four through six (point labeled $t=3$ in Figure 1)? As before, the normative salary would consist of the starting salary augmented by a historical cost-of-living adjustment for the first interval, a historical adjustment for the second one (year one to three), and an expected adjustment for the third one (year four through six):

$$
\mathrm{S}_{3,6}^{\mathrm{n}}=\mathrm{S}_{\mathrm{B}}+\mathrm{HCOLA}_{-3,0}+\mathrm{HCOLA}_{0,3}+\mathrm{ECOLA}_{3,6}
$$

Comparing equations (3) and (4) indicates that changes in the salary will be driven by the (i) difference between the historical and expected adjustments for the second interval, and (ii) expected adjustment for the third interval:

$$
\mathrm{S}_{3,6}^{\mathrm{n}}-\mathrm{S}_{0,3}^{\mathrm{n}}=\left(\mathrm{HCOLA}_{0,3}-\mathrm{ECOLA}_{0,3}\right)+\mathrm{ECOLA}_{3,6}
$$

The expected adjustment of the previous interval $\left(\mathrm{ECOLA}_{0,3}\right)$ is a historical adjustment for the current one $\left(\mathrm{HCOLA}_{0,3}\right)$. Thus, the sign of the bracketed term in Equation 5 depends on how inflation in years one through three compares with its expected value: it is positive (negative) if inflation was higher (lower) than expected, and zero if inflation was equal to its expected value. Consequently, changes in salary are driven by the interaction between this component and the expected adjustment for the next interval.

To illustrate, let us assume the price level at the end of year three to be 140, i.e. actual inflation $(3.032 \%)$ was higher than expected $(1.791 \%)$. Hence, the employee was undercompensated and should be given an additional $\$ 1,614.01$ ( $=\$ 5,291.24-\$ 3,677.23)$. If the price level is expected to increase to 145 at the end of year six, then the expected adjustment will be positive $(=\$ 3,734.22)$ and the salary will increase to $\$ 71,653.97(=\$ 66,305.74+$ $\$ 1,614.01+\$ 3,734.22)$. On the other hand, if the price level is expected to decrease to 129.11 , the magnitude of expected adjustment $(=\$ 1,614.47)$ will equal the payment for under compensation and the salary will remain unchanged: $\$ 66,305.74+\$ 1,614.01-\$ 1,614.47$. Finally, if the price level is expected to decrease to 125 , the magnitude of expected adjustment $(=-\$ 3,044.49)$ will be higher than the payment for under compensation and the salary will decrease to $\$ 64,875.26(=\$ 66,305.74+\$ 1,614.01-\$ 3,044.49)$.

The intuition developed above can be formulated mathematically and leads to the formula below for calculating the normative salary ${ }^{6}$.

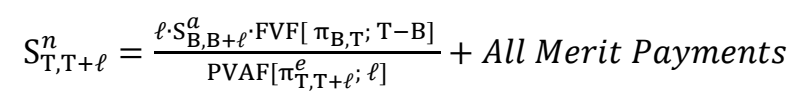

In this equation, $\mathrm{B}$ denotes the (in the past) year the individual started working, $\mathrm{T}$ denotes the current year, $\ell$ denotes the frequency of salary adjustments (e.g. $\square=3$ for adjustments made once every three years), $S_{B, B+\ell}^{a}$ denotes the starting salary, $\mathrm{S}_{\mathrm{T}, \mathrm{T}+\ell}^{n}$ denotes the normative salary for each of the next $\square$ years, $\pi_{\mathrm{B}, \mathrm{T}}$ denotes the annual inflation from year B through $\mathrm{T}, \pi_{\mathrm{T}, \mathrm{T}+\ell}^{e}$ denotes the expected annual inflation during the next $\square$ years, $\mathrm{FVF}\left[\pi_{\mathrm{B}, \mathrm{T}} ; \mathrm{T}-\mathrm{B}\right]$ is the future value factor-value of a dollar compounded at $\pi$ for T-B years: $\left(1+\pi_{\mathrm{B}, \mathrm{T}}\right)^{\mathrm{T}-\mathrm{B}}$, and PVAF[ $\left.\pi_{\mathrm{T}, \mathrm{T}+\ell}^{e} ; \ell\right]$ is the present value annuity factor-present value of an annuity that pays a dollar for the next $\square$ years at the rate $\pi_{\mathrm{T}, \mathrm{T}+\ell}^{e}$ : $\left[\frac{1-\left(1+\pi_{\mathrm{T}, \mathrm{T}+\ell}^{e}\right)^{-\ell}}{\pi_{\mathrm{T}, \mathrm{T}+\ell}}\right]$. The value of these factors can be calculated from Future Value Factor tables and Present Value Annuity Factor tables, respectively.

\section{COMPUTING THE NORMATIVE SALARY: A WORKSHEET}

This section utilizes the results of the previous section to develop a worksheet that can be used by employers to compute the normative salary for their employees. In contrast with the discussion in the pervious section, it includes all components of the normative salary - COLA, Merit Payment, and Incentive Payment.

\footnotetext{
${ }^{6}$ The proof is available upon request from the author.
} 
To illustrate the usage, consider an employee who started working for a company as a Junior Analyst at the end of 2003 at an annual salary of $\$ 55,000$. Since the employer has a policy of adjusting salaries every three years, he/she received this amount from 2004 through 2006. During this time period, the employee obtained an MBA degree from a local university. For this reason he/she received a Merit Payment of \$3,000 which increased his annual salary for 2007 through 2009 to $\$ 58,000$. At the end of 2009 , he/she was promoted to the position of Senior Analyst. This resulted in another Merit Payment of \$7,000 thereby increasing the annual salary for 2010 through 2012 to $\$ 65,000$ from $\$ 58,000$. The employee's performance for 2010 through 2012 has been rated Outstanding. It is currently the end of 2012, and the employer has to determine the employee's Cash Compensation for 2013 through 2015. This information is entered in Section A of the worksheet which is shown in Table 2.

Table 2: A Worksheet for Calculating the Cash Compensation of an Employee

\section{WORKSHEET FOR CALULATING CASH COMPENSATION}

Employee Name:

(A) Employment History

1. Year employee started working 2003

2. Starting Salary $\$ \$ 55,000$

3. Year of last salary adjustment $\quad 2009$

4. Current Year 2012

5. Year of next salary adjustment 2015

6. Total Merit Payments received since start-of-employment $\$ 10,000$

7. Frequency of salary adjustments 3

(B) Rate of Annual Inflation

8. Historical rate of inflation from the year in Line 1 to the year in Line 3

$2.68 \%$

$2.06 \%$

$2.47 \%$

$1.54 \%$

(C) Computing Relevant Numbers

12. Number of years between start of employment and last salary adjustment (=Line 3 - Line 1)

13. Number of years between start of employment and current year (=Line 4 - Line 1).

14. Future Value Factor based on the rate in Line 8 and number of years in Line 12.

15. Future Value Factor based on the rate in Line 10 and number of years in Line 13

16. Present Value Annuity Factor based on the rate in Line 9 and number of years in Line 7

17. Present Value Annuity Factor based on the rate in Line 11 and years in Line 7

(D) Computing Cash Compensation

(i) Adjustment for changes in cost-of-living:

18. Historical $\left(=\frac{\text { Line } 7 \times \text { Line } 2 \times \text { Line } 14}{\text { Line } 16}-\right.$ Line 2$)$

19. Expected $\left(=\frac{\text { Line } 7 \times \text { Line } 2 \times \text { Line } 15}{\text { Line } 17}-[\right.$ Line $2+$ Line 18] $)$

(ii) Merit Payments:

20. Historical Merit Payments (=Line 6)

21. Current Merit Payment

22. Normative Salary

(=Line 2+Line 18+Line 19+Line 20+Line 21)

23. Incentive Payment

24. Cash Compensation (=Line22+Line23)

Annual Payment (=Line 22)

One-Time Payment (= Line 23)
$\$ 12,031.25$

$\$ 3,845.04$

$\$ 10,000$

$\$ 2,500$

$\$ 83,376.29$

\begin{tabular}{ccc} 
Minimum & Expected & Maximum \\
\hline$\$ 0$ & $\$ 6,000$ & $\$ 10,000$ \\
$\$ 83,376.29$ & $\$ 89,376.29$ & $\$ 93,376.29$ \\
$\$ 83,376.29$ & $\$ 83,376.29$ & $\$ 83,376.29$ \\
$\$ 0$ & $\$ 6,000$ & $\$ 10,000$ \\
\hline
\end{tabular}


The next section collects information about historical and expected inflation. Historical inflation is calculated using the formula $\pi=\left(\frac{C P I_{T}}{C P I_{T-n}}\right)^{\frac{1}{n}}-1$, where $C P I_{(\cdot)}$ is the value of the Consumer Price Index at the end of year $(\cdot)$ and $\pi$ is the annual inflation from the end of year $T-n$ to the end of year $T$. Values for the Index can obtained from public data sources such as the St. Louis Federal Reserve (http://research.stlouisfed.org/fred2/). For example, the annual rate of inflation from the year of start of employment to year of last salary adjustment (Line 8) would be computed as $2.68 \%\left(=\left(\frac{215.949}{184.3}\right)^{\frac{1}{6}}-1\right)$. A similar process yields $2.06 \%$ and $2.47 \%$ for Lines 9 and 10 respectively. Similarly, estimates of expected inflation can be obtained from public websites such as the Cleveland Federal Reserve. The Cleveland Fed provides an Excel file containing estimates of expected inflation for all horizons at http://www.clevelandfed.org/research/data/inflation_expectations/index.cfm. The expected annual inflation at the end of 2012 for the next three years (2013-2015) was $1.54 \%$.

Section $\mathrm{C}$ computes various inputs that are required for computing components of Cash Compensation. To this end, it first computes the Future Value Factor based on (i) the historical rate of inflation and the number of years between the year of start of employment and year of most recent adjustment: $(1+0.0268)^{6}=1.17$, and (ii) the historical rate of inflation and the number of years between the year of start of employment and the current year: $(1+0.0247)^{9}=1.25$. Next, it computes the Present Value Annuity Factor using the (i) historical rate of inflation for the most recent three-year interval: $\left[\frac{1-(1+0.0206)^{-3}}{0.0206}\right]=2.88$, and (ii) expected rate of inflation for the next three-year interval: $\left[\frac{1-(1+0.0154)^{-3}}{0.0154}\right]=2.91$.

Using these inputs, the worksheet computes different components of Cash Compensation in Section D. The first component is a cost of living adjustment that accounts for the (i) historical change in prices: $\frac{3 \times \$ 55,000 \times 1.17}{2.88}-$ $\$ 55,000=\$ 12,031.25$, and (ii) expected change in prices: $\frac{3 \times \$ 55,000 \times 1.25}{2.91}-(\$ 55,000+\$ 12,031.25)=\$ 3,845.04$. The second component consists of historical and current Merit Payments. As described above, the merit payments received to date are worth $\$ 10,000(=\$ 3,000+\$ 7,000)$; the current merit payment will be based on the employee's performance from 2010 through 2012. Assuming the company awards a merit increase of $\$ 3,000$ for exceptional performance, $\$ 2,500$ for outstanding performance, and $\$ 1,000$ for performance that meets expectations, the current merit increase will be $\$ 2,500$. Adding the cost-of-living adjustments and merit increases to the starting salary gives us the normative salary of $\$ 83,376.29$. This is the minimum salary the employee must receive in each of the next three years (2013-2015).

The last component is the Incentive Payment. Let us assume that it is based entirely on company performance, as measured by a financial metric such as Sales, and computed as a fraction of performance in excess of a threshold value ${ }^{7}$. Specifically, an employee's incentive payment is calculated as:

$$
\text { IncentivePayment }=\gamma \cdot \max \left(0, \text { Sales }_{2012,2015}-\text { Threshold Sales }\right)
$$

Further, Sales for 2012 through 2015 are expected to be $\$ 6,200,000$ with a maximum value of $\$ 7,000,000$, the threshold value for Sales is $\$ 5,000,000$, and the proportion received by each employee is $0.5 \%$. This would imply an expected incentive payment of $\$ 6,000$ with a maximum value of $\$ 10,000$ (Line 23). Notice that the merit payments are based on an employee's past performance and result in permanent increases in his/her salary; incentive payments, on the other hand, are based on the future performance of the company and have to be re-earned in each time interval. The sum of the starting salary and these three components - cost of living adjustments, merit increases, and incentive payments - gives us the cash compensation for the employee. Although the worksheet is designed with an employer in mind, it can also be used by employees to gauge the appropriateness of their compensation.

\footnotetext{
${ }^{7}$ Incentive Payments are typically based on a combination of company performance, business group/department performance and individual contribution, and the amount is capped at a particular fraction of salary.
} 


\section{CONCLUSION}

This paper has developed a simple method for adjusting the compensation package of an employee over time. Using employee-specific inputs-starting salary, length of employment, and frequency of compensation adjustments-the method calculates the compensation at any time since the start of employment. It has several advantages. First, it can be easily integrated with an employer's existing compensation system -the existing performance evaluation method can be used to determine an employee's incentive and merit payment; these payments can then be used as inputs for the framework developed in this paper. Second, the framework is generic in the sense that the rate of inflation ( $\pi$ or $\pi^{e}$ ) in the formula can be replaced by one that better reflects an employee's experience. For example, the inflation in a geographical region (e.g. the Mid-West) might be different from the economy-wide inflation obtained via the CPI. In such cases, the rate of inflation should be computed from a regional price index to better reflect the price changes experienced by the firm's employees. Finally, the framework provides employers with a rational benchmark which can be used for compensation adjustments, especially for justifying decreases in compensation during recessions. In the past, determining an employee's compensation has been the outcome of an informed judgment of the management rather than of a scientific process or mathematical formula (Ch. 6 in Berger and Berger (2008)). The framework developed in this paper takes the first step in that direction.

\section{ACKNOWLEDGEMENTS}

The author thanks Leon Chen, Tunde Kovacs, Miles Smayling, participants at the 2014 Annual meeting of the Academy of Financial Services and especially Harry Thiewes for helpful comments, gratefully acknowledges a Summer Research Grant from the College of Business, Minnesota State University, Mankato, and is responsible for all errors.

\section{AUTHOR INFORMATION}

Puneet Jaiprakash is an Assistant Professor in the College of Business at Minnesota State University, Mankato, USA. He received his Ph.D. from Virginia Polytechnic Institute and State University (Virginia Tech). His research interests are primarily in the area of asset pricing, mutual funds, and behavioral finance. Email: puneet.jaiprakash@mnsu.edu

\section{REFERENCES}

Institute of International Finance, 2009, Compensation in Financial Services: Industry Progress and Agenda for Change.

Association of Financial Professional, 2013, AFP Compensation Report.

Berger, Lance A., and Dorothy R. Berger, 2008, The Compensation Handbook. 5th ed.

Murphy, Kevin J, 1999, Executive Compensation, in Orley Ashenfelter and David Card ed.: Handbook of Labor Economics. 3B ed. (Elsevier Science North Holland).

Newton, Catherine, 2002, Profiting from Compensation Strategies, Journal of Financial Planning 15, 68-74.

Pomering, Rebecca H., and Don C. Lyon, 2000, Compensation Survey an Important Benchmark in Employee Retention Efforts, Journal of Financial Planning 13, 48-53. 
NOTES 